\title{
Nutritional and socio-economic determinants of cognitive function and educational achievement of Aboriginal schoolchildren in rural Malaysia
}

\author{
Hesham M. Al-Mekhlafi, ${ }^{1,2 *}$, Mohammed A. Mahdy ${ }^{1,2}$, Atiya A. Sallam ${ }^{3}$, W. A. Ariffin ${ }^{4}$, \\ Abdulsalam M. Al-Mekhlafi ${ }^{1}$, Adel A. Amran ${ }^{5}$ and Johari Surin ${ }^{1}$ \\ ${ }^{1}$ Department of Parasitology, Faculty of Medicine, University of Malaya, Kuala Lumpur, Malaysia \\ ${ }^{2}$ Department of Parasitology, Faculty of Medicine, Sana'a University, Sana'a, Yemen \\ ${ }^{3}$ Department of Social and Preventive Medicine, Faculty of Medicine, University of Malaya, Kuala Lumpur, Malaysia \\ ${ }^{4}$ Department of Pediatrics, Faculty of Medicine, University of Malaya, Kuala Lumpur, Malaysia \\ ${ }^{5}$ Department of Physiology, Faculty of Medicine, Universiti Kebangsaan Malaysia, Jalan Raja Muda Abdul Aziz, \\ 50300 Kuala Lumpur, Malaysia
}

(Received 19 April 2010 - Revised 1 December 2010 - Accepted 21 February 2011 - First published online 15 April 2011)

\section{Abstract}

A community-based cross-sectional study was carried out among Aboriginal schoolchildren aged 7-12 years living in remote areas in Pos Betau, Pahang, Malaysia to investigate the potential determinants influencing the cognitive function and educational achievement of these children. Cognitive function was measured by intelligence quotient (IQ), while examination scores of selected school subjects were used in assessing educational achievement. Blood samples were collected to assess serum Fe status. All children were screened for soil-transmitted helminthes. Demographic and socio-economic data were collected using pre-tested questionnaires. Almost two-thirds (67.6\%) of the subjects had poor IQ and most of them (72.6\%) had insufficient educational achievement. Output of the stepwise multiple regression model showed that poor IQ was significantly associated with low household income which contributed the most to the regression variance $\left(r^{2} 0.059 ; P=0 \cdot 020\right)$. Low maternal education was also identified as a significant predictor of low IQ scores $\left(r^{2} 0.042 ; P=0.043\right)$. With educational achievement, Fe-deficiency anaemia (IDA) was the only variable to show significant association $\left(r^{2} 0 \cdot 025 ; P=0 \cdot 015\right)$. In conclusion, the cognitive function and educational achievement of Aboriginal schoolchildren are poor and influenced by household income, maternal education and IDA. Thus, effective and integrated measures to improve the nutritional and socio-economic status of rural children would have a pronounced positive effect on their education.

Key words: Cognitive function: Educational achievement: Nutrition: Socio-economic status: Aboriginal schoolchildren

Numerous factors are known to affect cognitive function (the mental processes by which knowledge is acquired including perception, reasoning, creativity, problem-solving and possible intuition measured by intelligence quotient (IQ)) and educational achievement of children (the progress of individuals in school measured by the results of examinations). Poor cognitive and educational performances among children can be attributed to a complex web of causation which involves insufficient infrastructure, health problems, poor socio-economic status and environmental causes. Health problems that may affect children's cognitive function and educational achievement include childhood infections ${ }^{(1,2)}$, malnutrition and micronutrient deficiencies including Fedeficiency anaemia (IDA) $)^{(3,4)}$, intestinal parasitic infections, mainly soil-transmitted helminthes $(\mathrm{STH})^{(5)}$, visual and hearing impairment ${ }^{(6)}$, epilepsy ${ }^{(7)}$ and many other problems. Moreover, stimulation-poor environments lead to poor development of the child's brain, which hinder the child's cognitive development ${ }^{(8,9)}$. Needless to say, poor socio-economic status is a strong inhibitor limiting educational achievement. Such a situation does not motivate children to study and an unsatisfactory home or class environment also does not encourage learning.

Orang Asli (a Malay term transliterated as 'original people') are the indigenous minority inhabitants of Peninsular Malaysia. They comprise only $0.6 \%$ of the total population in Malaysia (26.6 million in 2006). Despite intensive efforts by government and private sectors to improve the quality of life of Aboriginal communities throughout 53 years of independence (since 1957), little success has been achieved, and these communities are still plagued with poverty and a wide range of health problems. Very little is known about

Abbreviations: IDA, Fe-deficiency anaemia; IQ, intelligence quotient; STH, soil-transmitted helminthes; TS, total scores of the three school subjects. 
the cognitive functions and educational achievement of rural Aboriginal schoolchildren. Beside the expected shortage in educational facilities, the main problems that impede the educational process for Aboriginal people are poverty, poor health and nutritional status, and a high drop-out rate ${ }^{(10,11)}$. A national strategy to minimise the educational gap between rural and urban areas has been implemented and more than two million rural schoolchildren, including Aboriginal children, will benefit from this agenda. Hence, the present study was carried out to investigate the potential determinants that influence the cognitive function and educational achievement of Aboriginal schoolchildren in Peninsular Malaysia.

\section{Materials and methods}

\section{Study area and population}

The present study was carried out between August 2006 and January 2007. Selection of the study area was discussed with the Department of Aboriginal People Affairs and the following criteria were used to select the school: enrolment of more than 250 pupils, easy access and willingness of the teachers to cooperate. Sekolah Kebangsaan Betau (the Betau National School), a primary school for Aboriginal children in Pos Betau, Kuala Lipis, Pahang, Malaysia, met these criteria. The school had an enrolment of 405 pupils in the target age range of 7-12 years. Of these, sixty-nine were absent at the time of the visit, twenty-nine refused to participate and fifteen were excluded for having infections with fever.

This area is considered to be a remote area. Consisting of eighteen villages, it is located in a valley region about $50 \mathrm{~km}$ from the town of Kuala Lipis and $200 \mathrm{~km}$ northeast of Kuala Lumpur. There is a lack of sanitation with a high prevalence of intestinal parasitic infections, malnutrition and other health problems. There is a clinic in the area for health services equipped with an ambulance to send critical cases to the nearest hospital $(50 \mathrm{~km})$. Most of the residents work as farmers, labourers, rubber tappers and some do odd jobs such as selling forest products. Aboriginal individuals live in houses made of wood or bamboo. However, most of the houses have electricity during night-time only and a supply of piped water as the main source for drinking water while water for domestic needs (bathing, washing clothes and utensils and feeding animals) is collected from the rivers located adjacent to the villages.

Throughout many visits to the school and the villages, community meetings were held with the headmaster, heads of the villages, parents and their school-age children before the commencement of the present study in order to give a clear explanation of the objectives and the involvement of the children in the present study. Informed verbal consent was obtained from the participants; verbal consent was witnessed and formally recorded. The present study was conducted according to the guidelines laid down in the Declaration of Helsinki and all procedures involving human subjects were approved by the Medical Ethics Committee of the University of Malaya Medical Centre, University of Malaya, Malaysia.

\section{Study design and sample size}

The main design of the present study was a randomised placebo-controlled trial aimed at investigating the effects of vitamin A supplementation on the cognitive function and educational achievement of Aboriginal schoolchildren; the cross-sectional study described in the present paper served as a baseline assessment. A sample size of 214 children, 107 per intervention arm, was estimated to give the study at least $80 \%$ power at $5 \%$ significance to detect a significant difference in mean scores of IQ and total scores of the three school subjects (TS) between the vitamin A-supplemented group and the placebo group. Although this sample size included an extra $20 \%$ to avoid the effects of drop-out, we invited all children in the target age group to participate (universal sampling).

\section{Demographic and socio-economic data}

The demographic and socio-economic data of the subjects were collected using a pre-tested questionnaire constructed in English and then translated into Malay, the local language. Socio-economic status was assessed by a set of questions about the parents' educational and employment status, total household income and type and condition of houses. During the visits to the villages, the children and their parents were interviewed in their home settings by trained assistants to elicit information on the subjects' medical history, socioeconomic status and personal hygiene practices.

\section{Parasitology}

Fresh faecal samples were collected into wide-mouth screwcap $100 \mathrm{ml}$ clean containers. The samples were examined by the Kato-Katz technique ${ }^{(12)}$ for the presence of STH, Ascaris lumbricoides, Trichuris trichiura and hookworm eggs. Egg counts, as a measure of worm burden, were also carried out using this technique and the results were recorded as eggs per $\mathrm{g}$ of stool (epg). The intensity of infection was graded as heavy, moderate or light according to criteria proposed by the $\mathrm{WHO}^{(13)}$. Infections of moderate to heavy intensity are mainly responsible for the morbidity and health consequences due to $\mathrm{STH}^{(14)}$. Therefore, scores for the intensity of infections were given to each STH species (light $=1$, mild $=2$ and heavy $=3$ ) and infections with worm score $\geq 5$ were included in the analysis.

\section{Nutritional status assessment}

All subjects underwent physical examination including anthropometric measurements for weight and height. The children were weighed without shoes using a calibrated scale (Seca 709; Seca, Hamburg, Germany); height was measured by standing the child against a vertical wall, and marking off on the wall with the aid of a clipboard. Weight-for-age, height-for-age and weight-for-height $Z$-scores were used as indicators for underweight, stunting (chronic malnutrition) and wasting (acute malnutrition), respectively. The $Z$-scores 
were calculated using reference data from the National Center for Health Statistics (NCHS) and the WHO in EPI-Info for windows 2002 software (Centers for Disease Control and Prevention, Atlanta, GA, USA). Children who had a $Z$-score below -2 standard deviations of the NCHS reference population median values were considered to be significantly malnourished.

\section{Haematological and biochemical analysis}

About $2-3 \mathrm{ml}$ of venous blood were collected from each subject into a plain tube for biochemical analysis. Hb concentrations were measured directly after blood withdrawal using the HemoCue hemoglobinometer (HemoCue, AB, Angelhom, Sweden). Serum ferritin levels were analysed by means of the ADVIA Centaur Analyzer (Siemens Medical Solutions Diagnostics, Deerfield, IL, USA), and children with concentrations of less than $10 \mu \mathrm{g} / \mathrm{l}$ were considered to have deficient Fe stores. Meanwhile, serum Fe and total Fe-binding capacity (TIBC) were determined colorimetrically and then the percentage transferrin saturation was calculated from the ratio of serum $\mathrm{Fe}$ concentration:TIBC ${ }^{(15)}$. For quality control, 20\% of the samples were randomly selected and examined in duplicate. Children were identified to have IDA if they were anaemic and had low serum ferritin and/or low serum Fe, percentage transferrin saturation and high $\operatorname{TIBC}^{(16,17)}$.

\section{Cognitive function assessment}

IQ, also called cognitive function, was assessed using a Test of Nonverbal Intelligence, 3rd edition (TONI-3) which is a language-free, cognitive ability measurement tool for measuring abstract and figural problem solving, a major aspect of intelligence, in subjects ranging in age from 6 years 0 months to 89 years 11 months. The TONI kit has been used in assessing the cognitive function of rural children in Malaysia $^{(11)}$. The kit was administered to schoolchildren individually in a comfortable room which was well lit and free from noise. Tables provided in the manual were used to convert the raw scores into the corresponding IQ deviation quotients, which were then categorised into one of seven categories ranging from very poor to very superior, as follows: $>130$ (very superior); 121-130 (superior); 111-120 (above average); 90-110 (average); 80-89 (below average); 70-79 (poor); and $<70$ (very poor).

\section{Educational achievement assessment}

The assessment of educational achievement was based on the numerical marks of the end-of-semester examinations for three selected subjects, mathematics, English language and Malay language. The marks were collected from the records provided by the headmaster's office. These subjects represent the essential academic components which the student must pass in order to enter higher levels of education, and the Malay language was the medium of instruction for all subjects. Previous studies have used mathematics, English and national languages to assess the educational achievement of urban and rural schoolchildren in Malaysia and abroad ${ }^{(4,11,18)}$. For individual selected school subjects and overall results, the highest possible scores were 100 and 300, respectively. The test scores considered as sufficient achievement based on each subject (mathematics, English language and Malay language) and the total scores of the three subjects (TS) were $\geq 50$ or $\geq 150$, respectively.

\section{Statistics}

Statistical analysis of data was done using SPSS (version 13, September 2004; SPSS, Inc., Chicago, IL, USA). The distribution of IQ and TS measurements was examined using the Shapiro-Wilk test and found to be normal. For descriptive analysis, proportion was used to present the prevalence of categorical variables while mean or median was used to present the quantitative data. The independent $t$ test was used to compare the mean IQ and total educational achievement scores between groups. A significance level of 0.05 was used for all statistical tests. However, in order to retain all possible significant associations ${ }^{(19)}$, variables that showed association with a $P$ value $\leq 0 \cdot 20$ were used to develop a multiple linear regression model 'STEPWISE' to identify the determinants of cognitive function and educational achievement.

\section{Results}

A total of 292 schoolchildren agreed voluntarily to participate in the present study and delivered stool samples for examination. Of these children, only 241 children came for an interview to fill in the questionnaires and underwent a physical examination including anthropometry and cognitive function assessment. Therefore, the statistical analyses for the associations between the variables were based on this sample size.

\section{General characteristics of subjects}

The socio-economic and health characteristics of the subjects are shown in Table 1. They comprised 292 children (145 males; 147 females) aged between 7 and 12 years with a median age of 10 years (interquartile range 8-11 years). In general, poverty prevails in this area and about one-third of the fathers had formal education of at least 6 years while only $22.4 \%$ of the mothers had similar formal education. During the visits to the villages, we observed the poor personal hygiene of the children; they swim in the rivers very close to defecation sites, play bare-footed, consume unwashed fruits picked from the ground, eat without washing their hands and indulge in soil eating (geophagy).

\section{Health and nutritional status}

Almost all children (98.6\%) were infected either by one or more of the STH species. The overall prevalence of ascariasis, trichuriasis and hookworm infections was 67.8, 95.5 and $13.4 \%$, respectively. Almost one-third (29.8\%) of the children had heavy trichuriasis while $22.3 \%$ had heavy ascariasis. All hookworm infections in this population were light infections. 
Table 1. General characteristics of Aboriginal schoolchildren participants in the study ( $n$ 292)

\begin{tabular}{|c|c|}
\hline Characteristics & Frequency (\%) \\
\hline \multicolumn{2}{|l|}{ Age group } \\
\hline$\leq 10$ years & $69 \cdot 2$ \\
\hline$>10$ years & $30 \cdot 8$ \\
\hline \multicolumn{2}{|l|}{ Sex } \\
\hline Female & $50 \cdot 3$ \\
\hline \multicolumn{2}{|l|}{ Socio-economic status } \\
\hline Fathers' education level (at least 6 years) & $34 \cdot 3$ \\
\hline Mothers' education level (at least 6 years) & $22 \cdot 4$ \\
\hline Low household income $(<$ RM450) & $81 \cdot 2$ \\
\hline Working fathers & 51.4 \\
\hline Working mothers & $58 \cdot 1$ \\
\hline Large family size (eight or more members) & $35 \cdot 0$ \\
\hline Piped water supply & 87.4 \\
\hline \multicolumn{2}{|l|}{ Nutritional status } \\
\hline Significant underweight (weight-for-age $Z<-2$ ) & $37 \cdot 3$ \\
\hline Significant stunting (height-for-age $Z<-2$ ) & 43.6 \\
\hline Significant wasting (weight-for-height $Z<-2$ ) & $5 \cdot 6$ \\
\hline Fe-deficiency anaemia* ${ }^{*}$ & 34.0 \\
\hline \multicolumn{2}{|l|}{ Intestinal parasitic infections } \\
\hline Heavy ascariasis (mean epg > 50 000) & $22 \cdot 3$ \\
\hline Heavy trichuriasis (mean epg $>10000$ ) & $29 \cdot 8$ \\
\hline Hookworm infections & 13.4 \\
\hline Mixed STH infections & $62 \cdot 8$ \\
\hline
\end{tabular}

RM, Malaysian ringgit; epg, eggs per gram of stool; STH, soil-transmitted helminthes. ${ }^{*}$ Fe-deficiency anaemia: $\mathrm{Hb}$ concentration $<120 \mathrm{~g} / \mathrm{l}$, low serum ferritin $(<10 \mathrm{~g} / \mathrm{l})$ and/or low serum $\mathrm{Fe}(<10.6 \mathrm{mmol} / \mathrm{l})$, high total Fe-binding capacity $(>75 \mu \mathrm{mol} / \mathrm{l})$ and low transferrin saturation $(<16 \%)$.

The prevalence of mild and significant underweight was $52 \cdot 3$ and $37 \cdot 3 \%$, respectively, while the prevalence of mild stunting and wasting was 43.6 and $43.1 \%$, respectively, and of significant stunting and wasting was 43.6 and $5.6 \%$, respectively. Overall, 117 (48.5\%) children were anaemic $(\mathrm{Hb}<120 \mathrm{~g} / \mathrm{l})$ and the prevalence of IDA was $34 \%$, which accounted for $70 \cdot 1 \%$ of the anaemia cases among these subjects. Data on the prevalence of intestinal parasitic infections and IDA among these subjects have been published previously ${ }^{(20,21)}$.

\section{Cognitive function and educational achievement}

The mean IQ scores of these children was 76.4 (SD 5.4), which is considered as poor. The majority $(67 \cdot 6 \%)$ of the subjects were in the category of poor while 24.1 and $8.1 \%$ of them were in the category of below average and very poor, respectively. However, none of the subjects was distributed in the grades of above average, superior or very superior.
The mean educational score of each subject was low and most of the children $(72 \cdot 6 \%)$ had insufficient TS (Table 2). Moreover, $56.8 \%$ of the children had sufficient achievement for Malay language (mean score 50.9), whereas only 32.4 and $24.9 \%$ of them had sufficient scores for English language and mathematics, respectively.

\section{Determinants of low cognitive function and low educational achievement}

The differences in mean scores of IQ and TS in relation to some socio-economic, health, nutritional and demographic factors were examined and the results are shown in Table 3. Regarding the IQ (indicator of low cognitive function), children living in poverty (income $<450$ Malaysian ringgit (RM)) had significantly lower IQ scores $(t=3 \cdot 041 ; P=0 \cdot 007)$ than children from households with higher incomes. Similarly, the children of mothers with low educational levels had significantly lower IQ scores $(t=3.256 ; P=0 \cdot 001)$ than the children of mothers with at least 6 years of formal education. Children suffering IDA also had significantly lower IQ scores than non-anaemic children $(t=2 \cdot 140 ; P=0 \cdot 033)$.

With TS (indicator of low educational achievement), children infected with STH of moderate to heavy intensities (worm scores $\geq 5$ ) had significantly lower TS scores $(t=1.990$; $P=0.030)$ than non-infected children or those with light infections. Similarly, children of families with a low household income $(t=2 \cdot 251 ; P=0.025)$ and also those who were suffering from IDA $(t=2 \cdot 460 ; P=0 \cdot 007)$ had significantly lower TS scores than children of families with a monthly household income $>$ RM450 and those without IDA.

Stepwise multiple linear regression analyses were performed to identify the significant determinants of children's IQ and TS with control for the effects of possible confounders. The output of the models showed that IQ score was found to be significantly influenced by low household income which contributed the most to the regression variance $\left(r^{2} 0.059\right.$; $P=0.020)$, followed by low mothers' educational level ( $\left.r^{2} 0.042 ; P=0.043\right)$, while the non-significant variables $(P>0.05)$ were removed in a stepwise manner. In another model, the determinants of TS were identified after adding IQ score to the independent variables and controlling the effect of age; IDA was retained as the significant determinant of educational achievement $\left(r^{2} 0.025 ; P=0 \cdot 015\right)$.

Table 2. Educational achievement test scores of school subjects among Aboriginal schoolchildren ( $n$ 241)

(Mean values, standard deviations and ranges)

\begin{tabular}{lcccc}
\hline & \multicolumn{3}{c}{ Score } & \\
\cline { 2 - 3 } & & & & \\
Subject & Mean & SD & Range & $\begin{array}{c}\text { Percentage with test score } \\
\geq 50, \text { or } \geq 150 \text { for TS }\end{array}$ \\
\hline ML & 50.9 & $8 \cdot 7$ & $30-75$ & $56 \cdot 8$ \\
EL & 45.9 & 7.5 & $24-61$ & 32.4 \\
MT & 43.9 & 7.2 & $22-63$ & 24.9 \\
TS $^{*}$ & 140.6 & 14.9 & $107-184$ & 27.4
\end{tabular}

ML, Malay language; EL, English language; MT, mathematics; TS, total score.

${ }^{*} \mathrm{TS}=\mathrm{ML}+\mathrm{EL}+\mathrm{MT}$ 
Table 3. Univariate and multivariate analyses for scores of intelligence quotient (IQ) and total scores of educational achievement (TS) by socio-economic, health and nutritional factors among Aboriginal schoolchildren ( $n$ 241)‡

(Mean values and standard deviations)

\begin{tabular}{|c|c|c|c|c|c|c|}
\hline \multirow[b]{2}{*}{ Factors } & \multicolumn{3}{|c|}{ IQ } & \multicolumn{3}{|c|}{ TS } \\
\hline & Mean & SD & $t$ & Mean & SD & $t$ \\
\hline Sex & & & 0.603 & & & -1.139 \\
\hline Male & $76 \cdot 2$ & 5.4 & & $141 \cdot 7$ & $14 \cdot 3$ & \\
\hline Female & $76 \cdot 6$ & 5.5 & & 139.6 & $15 \cdot 6$ & \\
\hline Age group & & & 0.361 & & & $1 \cdot 248$ \\
\hline$\leq 10$ years & $76 \cdot 3$ & 5.4 & & $142 \cdot 5$ & $15 \cdot 5$ & \\
\hline$>10$ years & $76 \cdot 6$ & 5.5 & & 138.6 & $13 \cdot 0$ & \\
\hline Household income & & & $3.041^{*} \dagger$ & & & $2 \cdot 251^{*}$ \\
\hline$\geq \mathrm{RM} 450$ & 78.5 & $5 \cdot 3$ & & $145 \cdot 0$ & $15 \cdot 1$ & \\
\hline$<$ RM450 & $72 \cdot 9$ & $5 \cdot 0$ & & 139.6 & $14 \cdot 2$ & \\
\hline Fathers' education & & & $1 \cdot 260$ & & & 0.339 \\
\hline$\geq 6$ years formal education & 77.5 & $5 \cdot 7$ & & $140 \cdot 9$ & $15 \cdot 5$ & \\
\hline No formal education & $76 \cdot 5$ & $5 \cdot 4$ & & $140 \cdot 2$ & $14 \cdot 8$ & \\
\hline Mothers' education & & & $3 \cdot 256^{*} \dagger$ & & & 0.277 \\
\hline$\geq 6$ years formal education & $78 \cdot 7$ & 5.9 & & $142 \cdot 2$ & $14 \cdot 2$ & \\
\hline No formal education & $72 \cdot 1$ & $4 \cdot 8$ & & $140 \cdot 5$ & $13 \cdot 8$ & \\
\hline Mothers' employment status & & & 1.691 & & & $1 \cdot 125$ \\
\hline Working & $75 \cdot 9$ & $5 \cdot 2$ & & 139.7 & 14.5 & \\
\hline Not working & $77 \cdot 1$ & 5.6 & & 141.9 & $15 \cdot 6$ & \\
\hline Family size & & & 1.047 & & & 1.670 \\
\hline Eight or more members (large) & $75 \cdot 8$ & $5 \cdot 2$ & & $138 \cdot 1$ & $11 \cdot 0$ & \\
\hline Less than eight members & $76 \cdot 7$ & 5.5 & & $141 \cdot 7$ & $12 \cdot 9$ & \\
\hline STH infections (worm score $\geq 5$ ) & & & -0.340 & & & $1.990^{*}$ \\
\hline Moderate to heavy & $75 \cdot 3$ & 4.9 & & 137.7 & $12 \cdot 2$ & \\
\hline Negative to light & $76 \cdot 5$ & 6.5 & & $142 \cdot 8$ & $13 \cdot 8$ & \\
\hline Fe status & & & $2 \cdot 140^{*}$ & & & $2 \cdot 460^{*} \dagger$ \\
\hline IDA & $71 \cdot 8$ & $4 \cdot 2$ & & 135.4 & $10 \cdot 5$ & \\
\hline Non-anaemic & $76 \cdot 9$ & $5 \cdot 6$ & & $142 \cdot 3$ & $13 \cdot 3$ & \\
\hline Weight status & & & 0.820 & & & 0.193 \\
\hline Underweight & $76 \cdot 8$ & $5 \cdot 2$ & & $140 \cdot 9$ & $13 \cdot 1$ & \\
\hline Non-underweight & $76 \cdot 2$ & $5 \cdot 5$ & & $140 \cdot 5$ & $12 \cdot 3$ & \\
\hline Height status & & & 0.144 & & & 0.771 \\
\hline Stunted & $76 \cdot 4$ & $5 \cdot 4$ & & 139.8 & $13 \cdot 5$ & \\
\hline Non-stunted & $76 \cdot 5$ & 5.4 & & $141 \cdot 3$ & $12 \cdot 6$ & \\
\hline
\end{tabular}

RM, Malaysian ringgit; STH, soil-transmitted helminthes; IDA, Fe-deficiency anaemia

${ }^{*}$ Significant association $(P<0.05$; independent $t$ test).

$\dagger$ Confirmed as a significant determinant by multiple linear regression $(P<0.05)$.

$\ddagger$ Variables included in the multiple linear regression model were IDA, STH infections (worm score $\geq 5$ ), household income, family size and IQ score.

\section{Discussion}

The present study showed that the IQ grade of the subjects was poor and more than two-thirds of them had insufficient educational achievement. These findings are very similar to the results obtained by a previous study among Aboriginal schoolchildren in Perak, Malaysia ${ }^{(11)}$. On the other hand, the subjects of the present study showed lower cognitive function, represented by poor IQ, compared with children in other rural areas in Sarawak, East Malaysia ${ }^{(22)}$. Similarly, we found that the educational achievement of these children was much lower than rural children in Sarawak and those in urban areas $^{(12,22)}$. Studies from other countries have reported poor IQ and educational levels among rural schoolchildren ${ }^{(4,23)}$. These findings were not surprising as the rural areas usually lack well-equipped schools, expert teachers and sufficient infrastructure, including electricity. However, we observed that the school is well equipped with different facilities including a computer laboratory with Internet access, a library, and visual and science laboratories. It is generally accepted that poor socio-economic profile, parasitic infections, malnutrition, non-delivery of educational assistance, contrast in the pedagogy and the culture in Aboriginal communities could propagate the weaknesses in cognitive function and educational achievement.

Regarding the potential determinants of cognitive function and educational achievement, our findings were in accordance with previous studies from other countries that poverty, low educational level of parents ${ }^{(4)}$, malnutrition including micronutrient deficiencies ${ }^{(24,25)}$ and intestinal parasitic infections ${ }^{(23,26)}$ are major risk factors of insufficient cognitive and educational performance. We found higher IQ scores among children whose mothers had higher educational levels and whose families had higher monthly incomes. These findings are consistent with a previous study on urban primary schoolchildren in Selangor, Malaysia ${ }^{(10)}$. It is well known that educated parents play a crucial role in the educational process of their children. Poverty also limits educational achievement 
in different ways, with children of poor families being forced to work, which discourages their school attendance and performance.

Beside these factors, we found that children suffering from IDA were more prone to have lower cognitive function and educational achievement than non-anaemic children. Throughout previous reports, IDA has been conclusively seen to delay psychomotor development and impair the cognitive function of preschool and school-age children in Thailand $^{(4)}$, Indonesia ${ }^{(27)}$ and Zaire ${ }^{(24)}$. Moreover, a previous study found that schoolchildren from a non-institutionalised US population with Fe deficiency with or without anaemia had twice the risk of scoring insufficient mathematics scores than children with normal Fe status ${ }^{(25)}$. Furthermore, Fe supplements given to anaemic children and adults have been shown to produce significant improvements in their cognitive function and educational achievement ${ }^{(3,28-30)}$. Double-blind clinical trials aimed at assessing the effects of Fe deficiency on attention and learning processes in preschool and school-aged children found that IDA produces alterations in cognitive processes related to visual attention and concept acquisition and that these alterations are reversed with $\mathrm{Fe}$ treatment ${ }^{(27,31)}$. In contrast, previous studies reported that the poor scores in school subjects and cognitive functions tests of schoolchildren with IDA were not reversed by $\mathrm{Fe}$ supplementation $^{(32,33)}$.

Concern has been expressed about the potential impact of IDA on the cognitive function and psychomotor development of children throughout the neonatal, postnatal, infancy and childhood periods. A long-term study aimed at investigating the association of maternal Fe status by measuring umbilical cord serum ferritin concentrations and applying test scores of psychomotor development and functioning at 5 years of age showed that the children who had the lowest ferritin concentrations had significantly lower language ability and tractability than children who had higher ferritin concentrations ${ }^{(34)}$. In the same vein, a previous study found that children who had moderate anaemia as infants achieved lower IQ scores upon entry to school than did children who were non-anaemic during infancy ${ }^{(35)}$. These studies revealed that the effects of maternal Fe deficiency are not restricted to prematurity and impaired fetal growth, but also extend to abnormal psychomotor development and impaired cognitive function of these children in later life. Several mechanisms may explain the potential causal association between $\mathrm{Fe}$ deficiency and impaired cognitive and educational performance. Fe deficiency results in decreased body Fe stores, including decreased $\mathrm{Fe}$ in the central nervous system, even before erythrocyte production is affected ${ }^{(36)}$. In experimental animals, Fe has been shown to play a key role in brain function. Several areas of the brain contain Fe, sometimes in large quantities ${ }^{(37)}$, and Fe-deficient animals show alterations both in neurotransmitters and behaviour that do not usually respond to Fe replenishment ${ }^{(38)}$.

Meanwhile, the present study showed a lower educational achievement among children who were infected with STH of moderate to heavy intensities compared with those who were not infected or who harboured light STH infections.
The evidence that worms may affect cognitive function is largely circumstantial. More specifically, the clinical consequences of moderate and heavy infections with T. trichiura include stunting and $\operatorname{IDA}^{(16,39)}$, both of which are associated with impaired cognitive function and learning ability ${ }^{(25,27)}$. However, no significant association was reported between IDA and these infections among the subjects of the present study ${ }^{(21)}$. A previous double-blind placebo-controlled trial among Jamaican schoolchildren reported that moderate to high loads of $T$. trichiura infection have an adverse effect on certain cognitive functions but that this is reversible by therapy ${ }^{(23)}$. The mechanism by which parasitic infections impaired cognitive function and educational achievement could be directly through mediators in the systemic circulation including cellular and humoral immune responses to infections $^{(23)}$ or could be due to the fact that children infected with helminthes are lethargic and weak, and have frequent attacks of diarrhoea or dysentery and abdominal pain which may disturb the child's attention in the classroom.

Although the present study is the first, to our knowledge, to investigate the potential determinants influencing the cognitive function and educational achievement of Aboriginal schoolchildren in Peninsular Malaysia, some limitations related to study design (cross-sectional) should be considered when interpreting the study findings. Therefore, the present study demonstrated the association of cognitive and educational performance with socio-economic status and IDA but did not explain causality. Other potentially important determinants such as school-level factors (a viable curriculum, teachers' motivation, and a conducive learning environment) and family-level factors (home environment and parents' motivation) were not addressed in the present study.

In conclusion, the present study provides a communitybased figure for the cognitive and educational performance of Aboriginal schoolchildren, which was found to be poor and influenced by household income, maternal education and IDA. It is recommended that the School Health Service in Malaysia should also monitor the health and growth of primary schoolchildren. Effective and integrated measures to improve the socio-economic, nutritional and health status of Aboriginal and rural children would have a pronounced positive effect on their education.

\section{Acknowledgements}

The authors would like to acknowledge the headmaster, teachers and schoolchildren of Sekolah Kebangsaan Betau, the staff of the Department of Orang Asli Affairs, Ministry of Rural Development, and the staff of Clinic Pos Betau for their fruitful help. The present study was funded by the University of Malaya, Kuala Lumpur, Malaysia (research grant code PS178/2007B).

The contribution of the authors to the present study was: H. M. A., J. S., A. A. S. and W. A. A. were involved in the study design, analysis of data and writing of the manuscript; H. M. A., M. A. M., A. M. A. and A. A. A. collected the data. All authors read and approved the final manuscript.

There are no conflicts of interest. 


\section{References}

1. Lorntz B, Soares AM, Moore SR, et al. (2006) Early childhood diarrhea predicts impaired school performance. Pediatr Infect Dis J 25, 513-520.

2. Niehaus MD, Moore SR, Patrick PD, et al. (2002) Early childhood diarrhea is associated with diminished cognitive function 4 to 7 years later in children in a northeast Brazilian shantytown. Am J Trop Med Hyg 66, 590-593.

3. Stoltzfus R, Kvalsvig J, Chwaya H, et al. (2001) Effects of iron supplementation and anthelmintic treatment on motor and language development of preschool children in Zanzibar: double blind, placebo controlled study. BMJ 323, 1389-1393.

4. Sungthong R, Mo-suwan L \& Chongsuvivatwong V (2002) Effects of haemoglobin and serum ferritin on cognitive function in school children. Asia Pac J Clin Nutr 7, 245-255.

5. Nokes C \& Bundy DA (1994) Does helminth infection affect mental processing and academic achievement? Parasitol Today 10, 14-18.

6. Roberts JE, Burchinal MR \& Zeisel SA (2002) Otitis media in early childhood in relation to children's school-age language and academic skills. Pediatrics 110, 696-706.

7. Bourgeois BF (2004) Determining the effects of antiepileptic drugs on cognitive function in pediatric patients with epilepsy. J Child Neurol 19, Suppl. 1, S15-S24.

8. Thorsdottir I (2005) Supplement and stimulation for stunted children. Lancet 366, 1756-1758.

9. Walker SP, Chang SM, Powell CA, et al. (2005) Effects of early childhood psychosocial stimulation and nutritional supplementation on cognition and education in growth-stunted Jamaican children: prospective cohort study. Lancet 366, 1804-1807.

10. Zaini MZ, Lim CT, Low WY, et al. (2005) Effects of nutritional status on academic performance of Malaysian primary school children. Asia Pac J Public Health 17, 81-87.

11. Zaleha MI, Iskandar ZA, Khalid AK, et al. (2000) Effect of iodized oil supplementation on thyroid hormone levels and mental performance among Orang Asli schoolchildren and pregnant mothers in an endemic goiter area in Peninsular Malaysia. Asia Pac J Clin Nutr 9, 274-281.

12. Martin LK \& Beaver PC (1968) Evaluation of Kato thick smears technique for quantitative diagnosis of helminth infections. Am J Trop Med Hyg 17, 382-391.

13. World Health Organization (2002) Prevention and Control of Intestinal Parasitic Infections. Prevention and Control of Schistosomiasis and Soil-transmitted Helminthiasis. WHO Technical Report Series no. 912. Geneva: WHO.

14. Albonico M, Montresor A, Crompton DWT, et al. (2006) Intervention for the control of soil-transmitted helminthiasis in the community. Adv Parasitol 61, 311-348.

15. Blanck MH, Pfeiffer CM, Caudill SP, et al. (2003) Serum iron and iron-binding capacity: a round-robin interlaboratory comparison study. Clin Chem 49, 1672-1675.

16. Nor Aini U, Al-Mekhlafi HM, Azlin M, et al. (2007) Serum iron status in Orang Asli children living in endemic areas of soil-transmitted helminthes. Asia Pac J Clin Nutr 16, $724-730$

17. World Health Organization (2001) Iron Deficiency Anaemia: Assessment, Prevention, and Control. Geneva: WHO.

18. Zalilah MS, Jenny TB \& Nan EJ (2000) Nutrition and educational achievement of urban primary schoolchildren in Malaysia. Asia Pac J Clin Nutr 9, 264-273.

19. Bendel RB \& Afifi AA (1977) Comparison of stopping rules in forward regression. $J$ Am Stat Assoc 72, 46-53.

20. Al-Mekhlafi HM, Atiya AS, Lim YAL, et al. (2007) An unceasing problem: soil-transmitted helminthiases in rural Malaysian communities. Southeast Asian J Trop Med Public Health 38 998-1007.

21. Al-Mekhlafi HM, Surin J, Atiya AS, et al. (2008) Anaemia and iron deficiency anaemia among Aboriginal schoolchildren in rural Peninsular Malaysia: an update on a continuing problem. Trans $R$ Soc Trop Med Hyg 102, 1046-1052.

22. Zaleha MI, Hayati AR, Rizam AR, et al. (2003) Micronutrients and its correlation with mental performance among schoolchildren in Bario, Sarawak: a preliminary study. Med J Malaysia 58, 309-319.

23. Nokes C, Grantham-McGregor SM, Sawyer AW, et al. (1992) Moderate to heavy infections of Trichuris trichiura affect cognitive function in Jamaican school children. Parasitology 104, 539-547.

24. Boivin MJ \& Giordani B (1993) Improvements in cognitive performance for schoolchildren in Zaire, Africa, following an iron supplement and treatment for intestinal parasites. J Pediatr Psychol 18, 249-264.

25. Halterman JS, Kaczorowski JM, Aligne CA, et al. (2001) Iron deficiency and cognitive achievement among school-aged children and adolescents in the United States. Pediatrics 107, 1381-1386.

26. Ezeamama AE, Friedman JF, Acosta LP, et al. (2005) Helminth infection and cognitive impairment among Filipino children. Am J Trop Med Hyg 72, 540-548.

27. Soewondo S, Husaini MA \& Pollitt E (1989) Effects of iron deficiency on attention and learning processes in pre-school children: Bandung, Indonesia. Am J Clin Nutr 50, 667-674.

28. Aukett MA, Parks YA, Scott PH, et al. (1986) Treatment with iron increases weight gain and psychomotor development. Arch Dis Child 16, 849-857.

29. Soemantri AG, Pollitt E \& Kim I (1985) Iron deficiency anemia and educational achievement. Am J Clin Nutr $\mathbf{4 2}$, $1221-1228$

30. Murray-Kolb LE \& Beard JL (2007) Iron treatment normalizes cognitive functioning in young women. Am J Clin Nutr $\mathbf{8 5}$, $778-787$.

31. Seshadri S \& Gopaldas T (1989) Impact of iron supplementation on cognitive functions in preschool and school-aged children: the Indian experience. Am J Clin Nutr 50, 675-686.

32. Harahap H, Jahari AB, Husaini MA, et al. (2000) Effects of an energy and micronutrient supplement on iron deficiency anaemia, physical activity, and motor and mental development in undernourished children in Indonesia. Eur J Clin Nutr 54, Suppl. 2, S114-S119.

33. Pollitt E, Hathirat P, Kotchabhakdi NJ, et al. (1989) Iron deficiency and educational achievement in Thailand. $A m \mathrm{~J}$ Clin Nutr 50, 687-697.

34. Tamura T, Goldenberg RL, Hou J, et al. (2002) Cord serum ferritin concentrations and mental and psychomotor development of children at five years of age. J Pediatr 140, $165-170$.

35. Lozoff B, Jimenez E \& Wolf AW (1991) Long-term developmental outcome of infants with iron deficiency. $N$ Engl $J$ Med 325, 687-694.

36. Pollitt E \& Leibel RL (1976) Iron deficiency and behavior. J Pediatr 88, 372-381.

37. Dwork AJ, Lawler G, Zybert PA, et al. (1990) An autoradiographic study of the uptake and distribution of iron by the brain of the young rat. Brain Res 518, 31-39.

38. Beard JL (2001) Iron biology in immune function, muscle metabolism and neuronal functioning. J Nutr 131, Suppl. 2, S568-S579.

39. Cooper ES, Bundy DA, MacDonald TT, et al. (1990) Growth suppression in the Trichuris dysentery syndrome. Eur J Clin Nutr 44, 138-147. 